\title{
Justiça restaurativa na escola: um estudo sobre a implementação de mediação de conflitos e círculos restaurativos no Ceará
}

\author{
Restorative justice in school: a study on the implementation of \\ conflict mediation and restorative circles in Ceará
}

\author{
Katury Rayane Rodrigues Ramos \\ Rosemary de Oliveira Almeida \\ Sinara Mota Neves de Almeida
}

\section{Resumo}

A etnografia nos ajuda a pensar a escola pública brasileira ao analisar uma série de questôes que revelam um ambiente desafiador, muitas vezes, conflituoso. $\mathrm{O}$ olhar diferenciado para as relaçóes sociais entre os sujeitos escolares, como professores, alunos, núcleo diretivo e outros profissionais é significativo. Essas relaçóes sociais têm a possibilidade de serem reconstruídas e fundamentadas em um ambiente que visualiza os conflitos nas reais dimensôes, buscando as causas e pensando uma contralógica, a prevenção. Para isso, faz-se necessária a desnaturalização de uma cultura punitiva, que fundamenta e amplia os conflitos e a violência escolares. Este artigo traz reflexôes sobre a pesquisa "Mediação de conflitos e restauração da paz na Escola Pública: Narrativas e experiências", realizada na cidade de Fortaleza (Ceará-Brasil), por meio de iniciativas pioneiras para a implementação de um projeto de mediação de conflitos e práticas restaurativas nas escolas públicas do Ceará.

\section{Palavras-chave}

Escola Pública; Conflitos; Mediaçáo de Conflitos; Práticas Restaurativas.

\begin{abstract}
Ethnography helps us to think about the Brazilian public schools by analyzing a series of questions that reveal a often conflicting challenging environment. The differentiated look at the social relations among the school subjects, such as teachers, students, core board and other professionals is significant. These social relations have the possibility of being reconstructed and based on an environment that visualizes the conflicts in real dimensions, searching the causes and thinking the againstlogic, the prevention. In order to do so, it is necessary to denaturalize a punitive culture, which underlies and amplifies school conflicts and violence. This article reflects on the research "Conflict mediation and restoration of peace in the Public School: narratives and experiences", held in the city of Fortaleza (Ceará-Brazil), through pioneering initiatives for the implementation of a conflict mediation project and restorative practices in public schools in Ceará.
\end{abstract}

\section{Keywords}

Public school; Conflicts; Conflict Mediation; Restorative Practices. 
114 | Katury Ramos, Rosemary Almeida e Sinara Almeida

\section{Introdução}

A sociabilidade do ambiente escolar vem sendo condicionada por práticas de violência, pois o que se percebe nas observaçôes de pesquisa, mediante a escuta dos sujeitos escolares, é que o que fundamenta o cotidiano das relações sociais é a naturalização de violências diversas, bem como as resoluçóes dos conflitos, por meio de práticas punitivas que, muitas vezes, ampliam tais conflitos. A escola faz parte de um construto social baseado em instituições sociais modernas ocidentais. Nesse caso, a existência de um Estado moderno que legitima a violência é algo que merece nossas atenções e devidas preocupações, pois a escola reproduz açóes coercitivas fundamentadas na legalidade.

Sobre o paradigma da escola punitiva, é importante salientar que ações como a expulsão do aluno-problema, relações autoritárias de professores para com alunos e o exercício de violências simbólicas diversas representam uma construção baseada na organização de um Estado que resguarda as funções de administração de poderes. $\mathrm{O}$ cotidiano é construído a partir desses desequilíbrios e, desse modo, os conflitos são vistos como perturbadores da "ordem". Como estão inseridos dentro de uma cultura punitiva, imediatamente esses conflitos são interpretados como problemas, que devem ser combatidos, por meio da aplicação de penas e/ou da coerção. Consequentemente, o fenômeno gerador do conflito não é visualizado de forma efetiva, com a busca de suas causas e possíveis soluções preventivas. A reincidência e reprodução desse clima escolar são fundamentadas sob a aplicação de penalidades.

Neste artigo, partimos da compreensão de que a gestão escolar que busca resolver seus problemas relativos à violência e a conflitos sociais no interior da escola, por meio da mediação de conflitos, tem ampla possibilidade de favorecer um ambiente propício à pacificação social. Para alcançar este fim, urge a desnaturalização da punibilidade impregnada não apenas no campo jurídico, mas também em instituiçôes sociais como a escola, onde, na maioria das vezes, busca solucionar os conflitos por meio de puniçóes. Tal postura amplia os conflitos e as violências escolares, na medida em que surge um sentimento de aversão a uma prática reativa à repressão sofrida. Ao contrário desta postura, há a fundamentação que busca a restauração de laços entre pessoas em conflito, tendo como foco a utilizaçáo de práticas restaurativas, como a mediação de conflitos e os círculos de paz.

O processo de investigação foi vivenciado no ambiente escolar por meio da pesquisa "Mediação de conflitos e restauração da paz na Escola Pública: narrativas e experiências". A experiência descrita advém de iniciativas pioneiras, realizadas em escolas públicas da periferia da cidade de Fortaleza, por meio do Programa Mediação 
de Conflitos e Práticas Restaurativas, do Ministério Público do Ceará (MPCE) ${ }^{1}$, que estabeleceu um Convênio de Cooperação Técnica com a Secretaria de Educação do Estado do Ceará (SEDUC) e a Organização Não governamental Terre des Hommes $(\mathrm{ONG} \text { TDH})^{2}$, no início de 2013. Estas instituições já possuíam experiência de mediação de conflitos comunitária em núcleos espalhados em Fortaleza e em outras cidades do Ceará, bem como de mediação escolar e círculos de resolução de conflitos, em escolas públicas municipais, no bairro Bom Jardim, da cidade de Fortaleza.

As escolas ${ }^{3}$ selecionadas para a implementação do projeto "Mediação de Conflitos e Práticas Restaurativas nas Escolas" foram quatro: Didática (bairro Tancredo Neves), Paz (bairro Aerolândia), Fraternidade (bairro Dias Macedo) e Solidariedade (bairro Tancredo Neves), todas em bairros da Secretaria Executiva Regional VI da Cidadé ${ }^{4}$. Como campo de análise, acompanhamos mais especificamente a escola Ação, devido ao tempo e ao seu histórico de experiências diversificadas, direcionadas para a cultura de paz. Essa escola faz parte de outro projeto, chamado "Mediação de Conflitos: um Convite à Paz", que atua por meio de parcerias com o Ministério Público do Ceará, Núcleos de Mediação Comunitária do Ceará, Secretaria Municipal de Segurança Cidadã, Coordenadoria Municipal de Políticas Públicas sobre Drogas, Secretaria Estadual de Segurança Pública e Terre des Hommes Lausanne no Brasil e está situada na rede municipal de ensino.

Delineamos as reflexões principais a partir do objetivo central da pesquisa, a experiência de mediação de conflitos e as práticas restaurativas, em especial na última escola mencionada, à medida que as observaçóes e a inserção em campo foram sendo realizadas. Assim, construímos o problema e as questôes de pesquisa durante as primeiras inserções etnográficas nas escolas conveniadas ao programa e durante as leituras que formaram o estado da arte da mediação de conflitos e práticas restaurativas. Desta forma, questionamos: como se constitui uma experiência de cultura de paz por meio da mediação de conflitos e outras possíveis práticas de diálogo de paz, em um ambiente tenso como uma escola pública invadida pela

\footnotetext{
${ }^{1}$ Mais informaçóes em: <http://www.mpce.mp.br/>.

2 Para conhecer a instituiçáo, visitar site da TDH, disponível em: $<$ http://tdhbrasil.org/site/index.php>.

3 Em decorrência de conflitos enfatizados pelos próprios sujeitos da pesquisa em conversas e entrevistas, atribuem-se nomes fictícios às escolas e aos entrevistados.

${ }^{4}$ Fortaleza está dividida em Secretarias Regionais para efeito de sua administração. São sete regióes administrativas (Regionais I, II, III, IV, V, VI e Centro).
} 
conflitualidade e por casos de violência entre adolescentes? Que narrativas e práticas são encontradas no paradoxo do convívio da paz e da conflitualidade na escola?

Tais questôes são visualizadas em razão da escola, em especial na cidade de Fortaleza, apresentar casos de conflitos que a levam a ações agressivas como também se configurar em um espaço de possibilidades para a restauração do diálogo, como meio alternativo para resolução desses conflitos, por intermédio de iniciativas da gestão escolar, de pais, de alunos e da comunidade. Assim, nessa esfera de estudo, é necessária a relação conceitual com categorias analíticas que se configuram na reflexão sobre o universo escolar, como juventude, violência, conflitos, mediaçáo de conflitos escolares e práticas restaurativas.

\section{Construtos sociais e culturais: juventude e violência}

As definiçóes sobre infância, juventude e maturidade foram construídas ao longo de um processo histórico-cultural. Temáticas que vêm adquirindo vários contornos, conteúdos, formas sociais e legitimação jurídica no meio de disputas políticas e econômicas. Neste sentido, a maioria dos estudiosos dos contextos juvenis considera mais apropriado o conceito juventudes, com um significado baseado na pluralidade e em razão de sua dinamicidade, diferenças culturais, econômicas, familiares, grupais, entre tantas mençôes possíveis à condição juvenil com suas especificidades.

Nessa perspectiva, consideramos o ser jovem como aquele que vive "[...] num ambiente marcado por um vocabulário próprio, acompanhado de gostos específicos no vestir, relacionamento em grupo, namoro, dança, música, entre outras medidas sempre em modificação" (POCHMANN, 2014, p. 219). Para pensar a juventude, então, é necessário estabelecermos uma conexão com a ideia de que não se trata da estática noção da faixa etária, mas da dinâmica perspectiva da categoria social, ou seja, a juventude tem características específicas, não sendo uma mera continuação da infância e, sim, uma construção social e cultural que não pode ser definida exclusivamente por critérios biológicos ou jurídicos (ABRAMO, 1997).

Os estudos realizados nesta pesquisa mostram que o ambiente escolar é quase sempre fundamentado em torno de relaçóes conflituosas, também com casos graves de violência nas escolas da cidade de Fortaleza. É necessário fazermos um paralelo de que a violência também é uma construção, uma representação social e, por mais que se desdobre em vários tipos (física, simbólica, psicológica etc.), o que resulta, na realidade, é uma representação social construída, por meio dos fatos que ocorrem no cotidiano. 
A violência é facilmente definida como todo ato de coação, com consequências sobre a integridade física ou moral de pessoas. Dentro dessa ampla conceituação, a violência simbólica é um conceito importante para compreendermos a relação com a juventude. Trata-se de uma violência imperceptível e sutil, constituída pelas imposições e legitimação de práticas e valores pertencentes a grupos sociais dominantes sobre grupos dominados, que os aceitam como naturais, quase sempre inculcados de forma irrefletida e docilmente (BOURDIEU, 1989). Em consequência, essa violência se configura por meio da naturalização de ações de discriminaçáo e classificaçóes morais associadas a preconceitos de etnia, gênero, orientação sexual e religião, entre outros, podendo se transformar em tipos de violência física, como lesões graves e mortes violentas. Este aspecto configura uma das faces da produção atual da violência, podendo ser compreendido como uma construção social de "diabolização" do outro, facilmente atribuído a lugares ou grupos sociais alvo de preconceitos e estigmas, como jovens situados em bairros periféricos, em especial pobres e negros, conforme demonstra Wieviorka (1997).

Nesses bairros, convivem a violência e a luta contra ela, ainda fortemente marcadas por estigmas territoriais, que culminam em um processo de marginalização avançada das camadas mais pobres. Segundo Wacquant (2005, p. 195):

O estigma territorial apresenta uma tendência distinta em conglomerar-se e aglutinar-se em torno de áreas "barras-pesadas", "proibidas", que são claramente identificadas - não só por quem é de fora, mas por seus próprios residentes - como antros urbanos em privação, imoralidade e violência, onde apenas os párias suportariam viver.

Assim, crime e violência são conceitos criados, discurso e representação que, geralmente, suscita a associação entre violência e pobreza, estando a escola pública mergulhada na representação estereotipada do lugar de jovens indisciplinados e violentos. As violências de fato existem e são cada vez mais crescentes, envolvendo jovens, tanto como vítimas quanto como autores. Entretanto, é essa representação da criminalidade associada à juventude e à pobreza que traz a ideia de que eles são a própria representação do mal. É um desafio das políticas de prevenção acabar com essa argumentação desnecessária.

Os jovens pertencentes à escola pública, especialmente àquela situada em regiões menos favorecidas da cidade, têm sido alvos de sistemas classificatórios generalizantes que os colocam na categoria de "desviantes" dos padróes do estudante 
regular ou daqueles pertencentes à escola privada, tanto por referências a questóes externas, como o sistema escolar desestruturado e desqualificado, quanto em relação ao seu comportamento individual. A representação de violência na escola é relacionada ao lugar e à visibilidade do fato violento, quando alguém realiza ou sofre alguma ação violenta no cotidiano escolar, que é diferenciada da violência que ocorre no entorno da escola e no bairro. Por conseguinte, a visibilidade do fato violento é importante para a compreensão da violência na escola, na medida em que os jovens a percebem ou não na prática cotidiana. Percebemos, então, representações que naturalizam as práticas violentas, nos revelando a ideia de que tais práticas são entranhadas no espaço sagrado em sua versão cotidiana, microscópica, diferenciandose da rua quando se referem a assaltos e homicídios.

A mídia, como produtora em massa de informaçôes e formadora de opinióes, nem sempre baseada em fatos aprofundados, tem um papel crucial na naturalização do fenômeno da violência, contribuindo para a criação de espaços estereotipados e, muitas vezes, para a banalização da vida. Os programas policiais televisivos são peças fundamentais nessa construção "diabolizada" das mortes de jovens que ocorrem em bairros periféricos da cidade de Fortaleza.

Sob a pretensa explicação de "mostrar a violência e suas "causas", os meios de comunicação encontraram na violência um tema apropriado para explorar os sentimentos e as emoçóes dos indivíduos e, portanto, aumentarem seus índices de audiência (BARREIRA e BATISTA, 2011, p. 20).

Nesse sentido, o "mostrar" a violência revela o quanto a estigmatização territorial está presente e amplia a formação dos estereótipos, em torno do que seja um bairro violento ou daqueles que são agressores em potencial. Os bairros que se encontram nas periferias das grandes metrópoles são os que possuem uma população mais empobrecida e, portanto, estigmatizada como mais propensa às práticas de violência. Nesses espaços, há disputa territorial e a reflexão perpassa ao campo dos poderes.

A “territorialização" ou delimitação do "campo" configura o facto de jovens residentes em áreas nobres e ricas da cidade não passarem para o "lado de lá", nem os jovens do "lado de cá" passarem para o "lado de lá", pelo fato de não conhecerem as "regras", "códigos" e "protocolos", recebendo os estigmas $\mathrm{e}$ as barreiras sociais que são fruto dessas 
representaçóes realizadas sobre espaços sociais (FREITAS, BRASIL e ALMEIDA, 2012, p. 4).

A gestão da escola parece deparar-se com o desafio que significa não apenas a coordenação pedagógica do ensino-aprendizagem e o preparo dos indivíduos para a vida, mas a gestão da própria vida e da morte desses jovens, seja ela física, seja simbólica. Desse modo, o cotidiano das escolas, no cenário de violência urbana, tem mudado a prática escolar, pois é impactado por valores, linguagens e estéticas heterodoxas, advindas da lógica de organização de novas sociabilidades fora do ambiente escolar. Estes valores funcionam como substrato social, a partir do qual tanto jovens como demais agentes da escola formulam suas representaçóes sobre o que é crime e o que é ou não violento assim como orientam suas posturas básicas, diante dos conflitos cotidianos.

Um argumento significativo nas pesquisas sobre juventude e violência é o que descaracterizaria as construçôes de lugares e sujeitos violentos, que elegem jovens como preferenciais. Muitas vezes, nas ruas do bairro, na escola ou mesmo em casa, os jovens envolvem-se em situaçôes de conflito que não são tratadas como tais, fazendo acender um clima de violência exacerbada porque náo houve o cuidado adequado e oportuno de mediar esses conflitos. Os conflitos existem e devem ser conhecidos em sua diversidade, pois, como afirma Simmel (1983), são inerentes à vida social. Viver em sociedade é formar uma associação e faz parte da socialização humana viver em comum acordo, mas também lado a lado, com as tensões individuais e sociais que o viver junto acarreta. Trata-se de um processo de socialização contraditório. Os conflitos, portanto, são elementos centrais para entendermos a complexidade das práticas indisciplinadas dos estudantes nas escolas que, muitas vezes, tornam-se violentas. Os conflitos, por si, são inerentes à vida, fazem parte do cotidiano escolar e podem ser mediados e até explorados para uma mudança de atitudes.

Sem dúvida, um fenômeno recorrente que aparece nas discussões que se estabelecem entre professores, gestores e demais profissionais, praticamente em todas as escolas, é a indisciplina. Embora não constitua um fenômeno particular do atual contexto da educação brasileira nem seja restrito às escolas públicas, esse fenômeno expressa modos de pensar, sentir e de se posicionar dos jovens, em relação à instituição de ensino e manifesta, portanto, disposiçóes construídas em relação à experiência escolar. A indisciplina surge a partir de diversos fatores, entre eles o acúmulo de energia das crianças e adolescentes que, às vezes, frequentam instituições escolares sem quadras nem oferta de atividades esportivas para os alunos, durante os 
intervalos. Nos relatos de uma pesquisa sobre o Ensino Médio no Brasil, Abramoway e Garcia (2003, p. 384) comentam uma definição de indisciplina como:

Uma violação de regras acordadas ou estabelecidas dentro da escola é o que se pode denominar de indisciplina. Esse comportamento pode ser uma das consequências do desinteresse, e se caracteriza, segundo os alunos, professores e diretores, por conversas paralelas durante a explicação do professor, brincadeiras fora de hora, faltas excessivas e injustificadas e desrespeito aos horários.

Em vista disso, o problema se apresenta quando a representação sobre a indisciplina não se diferencia do conceito de infração ou ato infracional. A indisciplina viola regras na escola, promove conflitos, mas não é crime no sentido jurídico do termo. Neste sentido é que se percebe, na prática de mediação de conflitos na escola, a possibilidade de reverter esse significado das práticas indisciplinares e promover a paz e o retorno ao respeito.

\section{Resolução pacífica de conflitos: conceituação teórico- metodológica}

A mediação é uma metodologia de resolução de conflitos, por meio do estabelecimento do diálogo entre partes conflitivas, em busca de entendimento e restauração de laços. Práticas restaurativas são modos de resolução de conflito e violência que envolve, de forma voluntária, pessoas em situação de conflito: autor, vítima e representantes indicados pelas partes e/ou pessoas representantes de instituições de apoio. No caso das escolas em estudo, as práticas de restauração mais observadas foram a mediação de conflitos e os círculos de paz. De acordo com a ONG Terre des Hommes,

práticas restaurativas é o nome que se dá a um conjunto de metodologias de resolução positiva de situaçôes de conflitos, violências e atos infracionais [...] Tem como objetivo central a restauração. Ao lidar com os conflitos e violências, através das Práticas Restaurativas, não se intenta estabelecer culpados ou puniçóes, mas oportunizar-lhes o entendimento sobre as motivaçóes e necessidades que geraram os conflitos e atos violentos ou infracionais, restaurar as relaçóes entre as pessoas neles envolvidas, seus sentimentos consigo mesmas e, inclusive, reparar seu patrimônio, promovendo a segurança humana (TERRE DES HOMMES, 2013, p. 13). 
A mediação de conflitos, segundo Vezzulla (2004), é conhecida e aceita em vários lugares do mundo, chamando atenção para o fato de não ser apenas associada ao sistema jurídico, mas de um procedimento de abordagem informal de conflitos interpessoais. $\mathrm{O}$ autor expõe sobre a tradição da mediação no mundo ocidental, a partir da Universidade de Harvard. A mediação, portanto, é a atividade que se propóe a auxiliar um processo de comunicação entre as partes, com a facilitação de uma terceira pessoa "imparcial e neutra" (o mediador) - o autor prefere chamar de isenção porque não existe neutralidade - que permite a elas próprias falar sobre seus pontos de vista divergentes, compreender o conflito, suas necessidades e sentimentos, para, só então, procurar uma solução consensual. Retomar vínculos quebrados e o respeito entre as pessoas é a meta da mediação.

Apesar de parecer ser um fato recente, a mediação de conflitos não é novidade em muitas nações e culturas no mundo. Segundo Vianna (2009), na Antiga Roma, já havia o prenúncio do procedimento in jure (na presença do juiz) e o in judicio (na presença do mediador ou árbitro). No Oriente, ela é um procedimento comum. De acordo com Neto (2010), a mediação de conflitos origina-se na Antiguidade, por volta do ano de 700 a. C. Confúcio já preconizava que a mediação era a melhor forma de resolução de conflitos entre as pessoas, ajudadas por uma terceira pessoa imparcial, um mediador que se põe a facilitar o diálogo para que as pessoas envolvidas no processo de conflito conversem e possibilitem um acordo de forma autônoma.

Avançando mais na história, foi a partir da década de 1970, nos Estados Unidos, que experiências de mediação tomaram fôlego, tornando-se uma "teoria com a estruturação de mecanismos e técnicas de comunicação para sua institucionalização como método de resolução de conflitos voltado para os tempos atuais" (NETO, 2010, p. 22). Damos, assim, um salto para situar a mediação no Ocidente e melhor nos aproximarmos de nosso contexto.

Assim, há o entendimento de que tão ou mais importante do que conseguir um acordo entre as partes contrárias, é o tratamento do conflito, é o processo de compreensão das subjetividades presentes em uma sessão de mediação, os ditos e os não-ditos para alcançar a compreensão dos fatos.

Os conflitos subjetivos envolvem os relacionamentos, as emoçóes, os pontos de vista e as percepçóes diferentes de cada participante, assim como as falhas na comunicação e na compreensão dos fatos. Estes conflitos devem receber um tratamento especial, usando-se do respeito e 
da compreensão. São conflitos objetivos aqueles que envolvem questôes mensuráveis e concretas. Para a negociação cooperativa, a atenção do negociador deve estar centrada nos conflitos objetivos, contornando os conflitos subjetivos e separando-os dos objetivos para permitir assim seu tratamento (VEZZULLA, 2004, p. 68).

Essa análise é importante, porque vivemos em uma sociedade acostumada a não penetrar nos reais motivos dos conflitos. Nessa percepção, a subjetividade não é relevante, pois, muitas vezes, em situação de conflito, enfrentamos a situação de forma oposicionista ou a afastamos para debaixo do tapete - o que náo resolve. A mediação traz uma perspectiva diferenciada ao buscar a solução dos conflitos no tratamento e na busca significativa dos reais motivos dos conflitos. A figura do mediador é de suma importância para facilitar o processo da mediação. A citação abaixo explicita um conceito de mediação que concentra a definiçãa e as características do mediador:

Mediação, método dialógico de resolução de conflitos, consiste na intervenção de um terceiro, pessoa física, independente, imparcial, competente, diligente e escolhido em consenso, que coordena reunióes conjuntas ou separadas para que as pessoas envolvidas em conflitos construam conjuntamente a melhor e mais criativa solução. [...] Costuma-se afirmar que é eficaz na resolução de qualquer tipo de conflito onde existam vínculos passados ou a ser desenvolvidos no futuro entre as pessoas, sejam físicas ou jurídicas. A atividade baseia-se no princípio consagrado no Direito Contratual da Autonomia das Vontades, o que significa dizer que ela poderá ser utilizada se houver pessoas que, ao a conhecerem, a elegeram para buscar solução para seus conflitos (NETO, 2010, p. 19).

Compreendemos, no entanto, que o mediador, doravante chamado de imparcial ou isento, não é a encarnação da imparcialidade fria e distante. Ele exerce uma técnica, posto que é capacitado, mas não uma técnica pela técnica. O mediador não é necessariamente um juiz, um advogado, um professor ou qualquer profissional técnico. Principalmente quando falamos em mediação comunitária, estamos nos referindo àquela pessoa da comunidade ou, no caso da mediação escolar ${ }^{5}$, aos

\footnotetext{
5 A mediação escolar, em particular, é uma adaptação da mediação de conflitos, tendo surgido na década de 1970, nos Estados Unidos, motivada pelos contextos crescentes de violência. Essa técnica estendeu-se para a Europa, em especial para a França, na década de 1990 (ALMEIDA, 2009).
} 
profissionais da educação e aos estudantes que fazem o papel de mediador dentro do espaço da escola. São pessoas que estão em constante processo de se educar para mediar, independente do grau de instrução ou profissão; ele ou ela constitui-se o não sentenciador, mas simplesmente mediador de seres humanos e seus sentimentos, facilitador da comunicação que fará emergir a "identificação de interesses comuns, deixando livres as partes para explicarem seus anseios, descontentamentos e angústias" (SALES, 2004, p. 79).

Sobre o processo da realização da mediação, participamos de alguns atendimentos. Em um deles, o atendimento teve início com o acolhimento e as perguntas iniciais sobre o que ocorreu entre as alunas em conflito. Utilizamos a técnica de questionamentos, durante todo o diálogo. Diante das falas e expressóes gestuais das alunas, fizemos perguntas, como: o que aconteceu? Como foi o conflito? O que cada uma sentiu durante e depois do conflito? O que poderia ser feito por cada uma para amenizar a situação e não haver mais conflitos? Observamos que, a todo momento, uma das alunas demonstrava uma feição de indiferença às perguntas, agindo de forma debochada, sorrindo enquanto perguntávamos. A outra permaneceu ouvindo de forma engajada com a mediação, dizendo que estava disposta a esquecer o que aconteceu e recomeçar uma amizade com a colega. Nesse momento, ficamos emocionadas pela disposição e demonstração de humildade da menina, mas a outra colega de classe disse que não aceitava a amizade.

Notamos que, sobre os sentimentos revelados, o que ficou evidenciado foi a raiva dita por uma das alunas e o medo da outra. O acordo, dessa forma, apontava para a ideia de respeito uma a outra, porém sem amizade. A facilitadora da ONG $\mathrm{TDH}$, então, explicou que, depois desse acordo feito, se as partes, ou uma das partes, o descumprisse, ficaria a cargo da escola utilizar outras medidas, como suspensão ou até transferência. Dito isso, uma das alunas disse ser pouco a suspensão ou transferência para sua colega, demonstrando que não houve compreensão da situação. Ficou clara a repetição de uma delas que náo queria se comprometer com o acordo. Contudo, após as facilitadoras estimularem bastante a ideia do respeito, foi firmado o acordo entre as meninas.

Desta forma, a mediação, pelo estatuto de reflexividade que alcança, pode ecoar por muito tempo entre os mediados, fazendo-se luz que retira as sombras e ilumina os caminhos possíveis, não só para a resolutividade momentânea de um conflito, mas também para a aprendizagem da convivência diária com conflitos, que nos dá a todos a capacidade de resolvermos nossas próprias dissensões. Desse modo, é necessário que 
compreendamos bem o que significa imparcialidade, pois a pessoa que media guarda seus melhores sentimentos humanitários para com as duas partes conflitantes e também suas próprias necessidades. Sua tarefa é, além de tudo, silenciar seus próprios desejos para se pôr a facilitar, paciente e criativamente, o diálogo compreensivo entre os envolvidos em conflitos.

O processo de mediação tem uma sequência lógica, após a aceitação voluntária das partes envolvidas em um conflito. Antes de tudo, é relevante a preparaçáo e a análise profunda do caso, mediante informaçóes sobre a possibilidade de aplicação da questáo à mediação, evitando perda de aspectos significativos para incluir nos procedimentos da mediação. Há, primeiro, a pré-mediação, que corresponde ao atendimento das partes em separado, em que são ouvidas em suas necessidades e sentimentos; após esta ação, é marcado o dia da mediação. No início da mediação, o mediador explica o que significa esse procedimento, sua filosofia e ação prática, voltada para as expectativas de entendimento entre as partes em conflito que, de forma voluntária, passam a falar sobre seus problemas de maneira autônoma, sem necessidade de juiz ou advogados. Depois, estabelecem-se acordos de respeitabilidade, durante a sessão, para que as partes não se alterem e mantenham o diálogo.

Como vimos, para que haja mediação, é necessária a presença de uma terceira pessoa imparcial, que facilita o processo de diálogo entre as partes em conflito.

No espaço escolar, o mediador é aquele que proporciona a comunicação,
o diálogo e estabelece ligaçóes. Dessa forma, os educandos, através do
empoderamento resultante da mediação, aprendem a escutar, comunicar,
apresentar argumentos, avaliar soluçóes e alternativas e fortalecer tais
qualidades (BRASIL, BUSH e FOLGER, 1994 apud ALMEIDA, 2009,
p. 78).

A autora acrescenta que o mediador não traz soluções prontas, mas facilita a percepção dos mediados como sujeitos autônomos, capazes de resolverem seus próprios problemas, sem a necessidade de ter um juiz ou quaisquer autoridades lhe determinando o que fazer. Para ela: "Do mesmo modo, o professor não deve transferir conhecimento, mas criar possibilidades para a sua própria produção ou sua construção" (FREIRE, 2005 apud ALMEIDA, 2009, p. 78). Enfim, trata-se de adaptar os recursos da mediação comunitária na escola, com suas particularidades e desafios próprios.

Sendo o conflito parte inerente da vida de todo ser humano (SIMMEL, 1983), no caso da escola, entre indisciplinas e demais conflitos, pode-se perceber, 
além dos problemas, a ideia de oportunidade de transformar tais práticas em aprendizagem para os estudantes na escola e no mundo futuro que lhes vem. Como diz Almeida (2009), o conflito, ou melhor, saber lidar com ele, é uma habilidade que precisa ser incluída nos currículos escolares exatamente porque pode resolvê-lo e desenvolver responsabilidades. Ao resolver conflitos de pequena complexidade, evitase, assim, que estes se desenvolvam em crimes graves, gerando prevenção e estabelecimento da cultura de paz.

No bojo da mediação escolar, há outras práticas restaurativas de resolução de conflitos, como os círculos de paz, que se originam dos antigos círculos de diálogo comuns aos indígenas da América do Norte. Essa prática restaurativa foi redescoberta e praticada em várias partes do mundo, como retorno aos nossos ancestrais e aos valores comunitários. Os círculos de paz têm por objetivo propiciar um espaço de diálogo, por meio do qual se pretende, de forma coletiva, restaurar laços afetivos, além de reparar danos causados pelo conflito e promover as responsabilidades. Tratase de responsabilizar e não de punir, possibilitando a pacificação nos espaços de convivência comum. Dessa maneira:

O processo do Círculo é um processo que se realiza através do contar histórias. Cada pessoa tem uma história, e cada história oferece uma lição. No Círculo as pessoas se aproximam das vidas umas das outras através da partilha de histórias significativas para elas (PRANIS, 2010, p. 16).

Diz, ainda, a autora que:

Os Círculos de Construção de Paz reúnem a antiga sabedoria comunitária e o valor contemporâneo do respeito pelos dons, necessidades e diferenças individuais num processo que: respeita a presença e dignidade de cada participante; valoriza as contribuiçốes de todos os participantes; salienta a conexão entre todas as coisas; oferece apoio para a expressão emocional e espiritual; dá voz igual para todos (PRANIS, 2010, p. 18-19).

É importante dizer que, para que o círculo de paz ocorra, antes de tudo, é necessário que todos concordem, pois todo o processo se dá pela voluntariedade. É preciso também que os envolvidos compreendam valores comunitários de respeitabilidade e convivência fraterna, além do sentimento de verdade, confiança, 
perdão e compaixão, entre outros, já que todos deverão ser honestos, assumindo suas responsabilidades.

A sequência dos círculos configura-se da seguinte forma: 1) pré-círculo, em que o mediador ouve uma parte, ouve a outra em separado, depois conversa com os contatos de apoio dos dois lados e marca o dia do círculo; 2) o círculo é o momento do encontro entre todos os envolvidos no conflito e os convidados para o apoio, em que se sentam em círculo e conversam com a orientação de um facilitador e com o uso do "bastão da fala" para chegar a processos decisórios de forma consensual. Geralmente, o facilitador prepara o ambiente de forma lúdica, enfeitando o círculo com a denominada "Peça de Centro", que é uma toalha ou manta, posta no chão, com vários objetos, cuja ideia é visualizar símbolos facilitadores da boa lembrança e do entendimento; 3) por fim, marca-se um novo encontro denominado de PósCírculo, para averiguar como as partes estão se sentindo e agindo, após algum tempo.

O trabalho de campo na escola Ação ocorreu, inicialmente, por meio das visitas às escolas e do acompanhamento ao trabalho das facilitadoras que já desenvolviam as práticas restaurativas, mediante a mediação de conflitos, os círculos de paz e círculos restaurativos, os chamados processos circulares. Lá pudemos observar, na prática, o que aprendemos, durante as oficinas e o grupo de estudos nas escolas estaduais. A mediação e, principalmente, os processos circulares (prática mais utilizada nesta escola) são constituídos por muito mais do que apenas pessoas organizadas em círculos. Eles remetem a uma conexão igualitária entre todos os participantes, ou seja, não há uma hierarquia e, sim, unidade. Assim, todos podem ver todos e são vistos por todos. Participamos de pré-círculos, entendendo a ideia da escuta ativa - ou seja, ouvir a todos para, em seguida, propor o círculo -, de círculos e de mediações também.

$\mathrm{Na}$ escola Ação, observamos que alguns casos acabavam sendo resolvidos ainda no pré-círculo, promovendo já o entendimento entre as partes em conflito. Quando aconteciam os círculos, o que mais nos chamou a atenção foi o uso do bastão da fala, aquele elemento que auxilia o controle da fala e da escuta, no processo circular, como havíamos aprendido, durante os estudos de todo o processo circular, com base nos guias do TDH. Assim, observamos que, sempre que acontecia um

\footnotetext{
${ }^{6}$ O bastão da fala é um objeto simbólico escolhido pelo facilitador do círculo de diálogo para representar o poder da fala, ou seja, quem estiver com o bastão tem o momento da fala, enquanto os demais ficam ouvindo. A ideia é que o bastáo circule e todos possam falar.
} 
círculo, a facilitadora tomava um objeto, que seria o bastão da fala, e o apresentava aos participantes, explicando detalhadamente o seu uso. Várias vezes, observamos o uso de um coração cor-de-rosa, simbolizando amor e amizade, e percebíamos que funcionava, de fato, como regulador da fala, não no sentido de podá-la, mas, ao contrário, de deixar a pessoa que o sustentasse falar e ser ouvida. Ao terminar, ela passava no sentido circular e, assim, seguia até que todos falassem. Claro que, na prática, nem tudo ocorria exatamente como aprendemos na teoria: em algumas vezes, alguns tentavam atropelar a fala do outro, mas, ao lembrar do bastão da fala, estes se retraíam. No final do processo, era feito um acordo entre as partes, que se comprometiam com o acordo firmado. Isto, no entanto, não obriga a existência de um relacionamento ou significa que necessariamente se constitui, a partir de entáo, uma amizade entre as partes, mas, sim, que se desenha uma relação de respeito e educação. A etapa final era o Pós-círculo, que é um acompanhamento, uma avaliação sobre o cumprimento ou não dos acordos firmados.

\section{Procedimentos metodológicos}

A metodologia é etnográfica, em relação aos passos instituidores da mediação escolar nas escolas conveniadas. Entendemos por etnografia a perspectiva metodológica que privilegia o ponto de vista nativo, a partir de como os sujeitos da pesquisa refletem e dão sentido às próprias experiências (GEERTZ, 2008). O pressuposto é se embrenhar em experiências bem definidas, mergulhar em campo específico para análise dos fenômenos particulares.

No caso em questão, nos inserimos nas escolas para compreender as práticas conflitivas e de resolução de tais conflitos, mediante a etnografia de eventos escolares cotidianos, de experiências de aulas, de rituais pedagógicos, de dramas e festas enfim, dos retratos conflituosos e passíveis de mudanças pela prática da mediação e resolução de conflitos. Assim, houve a aproximação nos discursos, pontos de vista, representaçôes e experiências dos sujeitos que fazem as escolas pesquisadas. Iniciamos o acompanhamento etnográfico com a participação, já nas primeiras visitas realizadas às escolas, para levantamento do contexto escolar em termos de análise da infraestrutura, projeto pedagógico e cotidianidade da escola. Nesses momentos, também fizemos levantamento de demandas de conflitos pelos sujeitos escolares, mediante aplicação de questionários, entrevistas e observação do dia a dia escolar, bem como estudos teóricos para a compreensão ampla da conflitualidade e da violência nas escolas. 
Outro recurso metodológico foi o envolvimento dos pesquisadores em atitude colaborativa com as instituiçóes que estáo realizando o processo de implantação da mediação escolar e práticas restaurativas, a saber: Ministério Público do Ceará (MPCE), Terre des Hommes (TDH) e Secretaria de Educação do Ceará (SEDUC). A esse envolvimento, Almeida (2009) denominou de metodologia colaborativa entre pesquisador e pesquisados. Portanto, houve participação e acompanhamento dos passos do projeto do MP, SEDUC e TDH (este com o peso da metodologia e técnicas de implantação da mediação e práticas restaurativas), descrevendo-os e agindo mediante a observaçáo participante, em todo o desenvolvimento do projeto, primando pela objetividade da pesquisa.

Entre nossos objetivos estava o de realizar o diagnóstico das escolas conveniadas, para conhecer seus contextos socioculturais e suas formas de resolver os conflitos e enfrentar violências. De posse do processo de implantação das práticas restaurativas, com base nas etapas construídas pela $\mathrm{TDH}$, percebemos que não deveríamos utilizar outra metodologia, mas, sim, participar da proposta desta instituição, observando e colaborando com sua realização. Sobre o diagnóstico, trabalhamos mediante um calendário de entrevistas e questionários (aplicados aos gestores, professores, funcionários, familiares e alunos), observação e sistematização dos dados e construção dos indicadores qualitativos e quantitativos.

As primeiras observaçóes ocorreram com as visitas às escolas para conhecimento inicial e aplicação dos questionários. Dirigimo-nos às escolas Fraternidade e Solidariedade, que nos pareceram ter maior infraestrutura física e humana. A primeira possui uma entrada bem ampla e está localizada ao lado de um mosteiro. Algo que se destaca como primeira impressão é a presença de árvores e plantas, logo na frente, um jardim em construção. No espaço físico da escola, de uma forma geral, percebe-se uma preservação do local e salas de aulas com boa ventilação. $\mathrm{Na}$ segunda escola, também apreciamos um clima bom, sendo menor do que a Fraternidade. As dependências da secretaria e direção são diferentes, são salas independentes. Antes de iniciarmos a aplicação dos questionários com profissionais e alunos da escola, observamos a presença de Dona Roberta - que uma funcionária denominou de "patrimônio da escola". Trata-se de uma senhora idosa que permanece no período da manhã, de forma voluntária, "vigiando" os alunos, disciplinando-os para entrarem nas salas de aula.

Mediante informações coletadas, identificamos a existência de conflitos de baixa complexidade nas dependências das escolas, como nas filas (empurróes, brincadeiras), o que a diferencia de seus arredores, geralmente marcados por conflitos 
armados e assaltos próximos ao prédio da escola, dado comentado por todos os segmentos entrevistados. Percebemos haver certo controle no interior da escola, no que se refere à disciplina - dado mais comentado pela escola Didática - e busca de solução de conflitos entre alunos por parte da gestão e dos profissionais entrevistados, o que nos pareceu ser um ponto forte para um trabalho com as práticas restaurativas.

Por outro lado, percebemos, pelos questionários e observações, a existência de conflitos como roubos de objetos em sala de aula e brigas. Uma das coordenadoras do núcleo gestor da escola Solidariedade, para nossa surpresa, se dirigiu até nós, pegando um aluno pelo braço, nos apresentando e dizendo: "como este, diariamente há uma rotina de conflitos entre alunos, como rasgar mochilas uns dos outros como revide (exemplificando o caso do aluno que estava com a mochila rasgada), casos de furto em sala de aula e vários"; e saiu, puxando o aluno. Isso quis dizer, a nosso ver, que o conflito existe e tem havido formas de controle, porém, sem necessariamente fortalecer a forma de mediá-lo, com o diálogo, em especial, o atendimento mais amplo e as formas de organização política da escola, como conselhos, grêmios etc ${ }^{7}$. Diagnosticamos, neste instante, espaço propício para a implantação das práticas restaurativas, em especial, por detectarmos a presença de pessoas com perfil mais próximo do mediador e a existência de casos que necessitavam da mediação e de círculos de resolução de conflitos.

Tivemos acesso a um relatório de execução do projeto da $\mathrm{TDH}$, em dezembro de 2013, que revelou situaçóes de violência verbal entre pessoas do núcleo gestor das escolas e alunos, entre professores e estudantes, dos estudantes entre si, em especial, com xingamentos, gritos e condutas autoritárias. Nas observaçôes e questionários, percebemos que todos da escola declararam que há pouca violência no interior das escolas e que há mais nos bairros, relatando casos de assassinatos, briga de gangues e que, nas escolas, ocorrem mais brigas, agressões físicas e desentendimentos.

Pelos questionários aplicados aos profissionais, das 40 respostas dadas à questão "se existe/existiu alguma situação que deixou insegurança ou medo", houve 16 respostas afirmativas e 24 negativas, corroborando a percepção de que há controle do medo e do conflito no interior da escola. Porém, há um dado relevante na questão "nos últimos 12 meses, você vivenciou algum conflito na escola", pois as respostas se dividiram entre $50 \%$ para o sim e $50 \%$ para o não. Ou seja, há conflitos relevantes a serem mediados, embora haja certo controle.

\footnotetext{
${ }^{7}$ Percebemos a inexistência ou desativação desses organismos nas escolas.
} 
Outra escola teve destaque nas atividades de mediação. Trata-se da escola Ação, gerenciada pelo município de Fortaleza e que não se inscreve no projeto de cooperação entre SEDUC, TDH e MP-CE, mas é um projeto da TDH, em parceria com o MPCE e a própria escola. Nesta, o processo de implantação, as formações e a capacitação de mediadores e facilitadores já se efetivaram, além do compromisso do núcleo gestor da escola e a existência de um espaço ou sala de mediação, que conta com mediadores alunos e profissionais da escola. Busca, agora, se consolidar na experiência, em meio aos conflitos internos e externos e dificuldades cotidianas.

Diante da estratégia metodológica utilizada, é interessante ressaltarmos que, nas observações e ações colaborativas em campo, houve uma ocorrência maior de círculos de diálogos e a técnica da mediação foi utilizada em alguns casos. A primeira etapa da dinâmica de implantação refere-se à análise de contexto (ou análise situacional ou, ainda, diagnóstico do espaço escolar), que ocorre por meio das visitas, aplicação de questionários e observações, realização de entrevistas, observação direta, grupo focal, aplicação de questionários etc. Tivemos oportunidade de participar mais ativamente desta etapa, nas escolas Solidariedade e Fraternidade, realizando entrevistas e aplicando questionários com alunos, profissionais e familiares.

\section{Considerações finais}

A escola pública é uma instituição significativa para este trabalho que, não bastando os condicionamentos relativos às políticas educacionais no Brasil, tem sido acometida por atos conflituosos e violentos, em seus arredores e mesmo no seu interior. Essa situação promove extensa discussão sobre as possibilidades de a escola ainda ser considerada um espaço sagrado para jovens, no seu processo de aprendizagem e profissionalização, ou ter evoluído para ser apenas mais um ambiente inseguro, em tempos de violência exacerbada. Estudar políticas educacionais voltadas para a escola pública, a gestão democrática, o projeto político-pedagógico, a cultura escolar e as práticas cotidianas escolares envolvidas em situaçôes de conflito e violência, entre outros temas, é fundamental para o despertar da escola e de sua função social. São desafios, assim como o é a busca de compreensão das experiências de cultura de paz nas escolas, como é o caso da pesquisa ora em questão.

A filosofia da mediação de conflitos culmina na experimentação de uma relação dialógica entre partes que estão com algum tipo de conflito interpessoal, no sentido de promover o entendimento entre as pessoas, com a mediação da sessão feita por uma terceira pessoa isenta daquele conflito. Não é difícil perceber que, ao contrário desta concepção, vivemos sob o manto de uma sociedade judicializada, em 
que a norma jurídica, em uma situação de conflito, impóe quem está "correto" para ganhar "a causa" e quem irá perder determinada disputa.

Facilmente, podemos observar que, algumas vezes, as relações entre a autoridade escolar (professores, coordenadores, entre outros) e o estudante assim como as relações entre a autoridade legalmente constituída nas Secretarias de Educação e os profissionais da educação lotados em escolas públicas são baseadas na imposição e não no diálogo - em outras palavras, muitas vezes, essas relações se dão de forma autoritária e não baseadas no conceito de autoridade constituída para o bem comum. Ocorre algo ainda mais grave: algumas vezes, os problemas são deixados para se resolver de forma interpessoal ou deixados para lá, diante da falta de diálogo que, por sua vez, tem sido motivado pelos círculos corriqueiros de desinteresse, descaso pela educação e das práticas indisciplinadas. Assim, passa-se sem discussão pedagógica e sociológica sobre as disposições adquiridas e criadas nas estruturas sociais e mentais das quais os indivíduos criam e recriam suas práticas, em que surgem os conflitos. Trata-se de um Estado penal repressivo, que não exercita práticas preventivas e de resolução pacífica de conflitos, mas detém uma lógica punitiva e uma justiça que condena um e liberta outro, repara uns em detrimento de outros.

Em contrapartida, a proposição da mediação de conflitos e das práticas restaurativas (no caso específico desta pesquisa, em ambiente escolar), é que a escola e seus sujeitos possam almejar uma formação científica baseada em temas e conteúdos próprios de sua matriz curricular, bem como vinculada a conceitos que favorecem a capacidade reflexiva dos alunos, que estimule os conflitos como meios de argumentação necessária frente às próprias problemáticas vivenciadas pelos estudantes na sua realidade. Mudanças significativas e processos de identificação com a escola poderão surgir por meio do diálogo sobre conflitos existentes, de modo a envolver alunos e demais sujeitos no contexto escolar, de tal forma que se reconheçam capazes de identificar os problemas que estáo colocados e que se sintam instigados a procurar soluçóes efetivas.

Um fator positivo é que o projeto foi implantado, mesmo faltando ainda, em alguns casos, fortalecimento e maior empoderamento das escolas e das comunidades em que se inserem. A gestão do projeto só será percebida com certo tempo, quando as escolas assumirem a tarefa de forma autônoma. $\mathrm{O}$ trabalho continua, embora com todos esses problemas, estando algumas escolas com maior dificuldade de continuidade e outras, com um pouco mais de investimento, por parte dos profissionais. No entanto, todas as escolas foram motivadas pelas capacitaçóes da 
mediação e práticas restaurativas que, de uma forma ou de outra, penetram nas consciências e atitudes de alguns profissionais como desafio permanente.

Além disso, faltam às escolas maior acompanhamento e fortalecimento de redes comunitárias, ou seja, maior integração com as comunidades nas quais estão inseridas e com suas organizaçôes sociais e culturais. No diagnóstico, visualizamos a presença de Centros de Referência Especializada e Assistência Social (CREAS), associaçóes, igrejas, polícias, MPCE, Defensoria Pública, entre outros, que poderiam se instituir em rede de enfrentamento à violência e para a garantia dos direitos da populaçáo. Isto é importante, configurando-se a etapa do fortalecimento das escolas e da comunidade para se empoderarem e alcançarem a gestão autônoma de seus conflitos.

Portanto, com esta pesquisa, percebemos que há espaço concreto de realização das práticas restaurativas, dentre elas a mediação de conflitos, nas escolas, realizando suas técnicas de resolução de situações conflituosas, violentas ou de atos infracionais, a partir da participação de pessoas capacitadas, autores e receptores espontaneamente e demais representantes da comunidade. Desse modo, é importante lembrarmos que o objetivo central destas técnicas é criar um espaço saudável de diálogo sobre o conflito, para a busca de restauração dos laços perdidos, de reparo de danos e de promoção de responsabilidades de todos os envolvidos, almejando, com isto, promover a paz na escola e na comunidade. 
Katury Rayane Rodrigues Ramos é Doutoranda em Ciências Sociais, pelo Programa de pós-graduação em Ciências Sociais da Universidade Federal do Rio Grande do Norte (UFRN) e Mediadora de Conflitos pelo Ministério Público do Estado do Ceará (MPCE) e pela ONG Terre des hommes (ONG TDH/2012). E-mail: katuryrayane@hotmail.com.

Rosemary de Oliveira Almeida é Doutora em Sociologia, pela Universidade Federal do Ceará (UFC). E Professora da Universidade Estadual do Ceará (UECE).

E-mail: rosemary.almeida67@gmail.com.

Sinara Mota Neves de Almeida é Doutora em Educação Brasileira, pela UFC. E Professora da Universidade da Integração Internacional da Lusofonia Afro-Brasileira (UNILAB) e Membro do Grupo de Pesquisa e Extensão ELOSS (Educação e Cooperação Sul-Sul).E-mail: sinaramota@unilab.edu.br.

\section{Referências}

ABRAMO, Helena Wendel. Considerações sobre a tematização social da juventude no Brasil. Revista Brasileira de Educação. ANPED, São Paulo, n. 5, p. 25-36, 1997.

ABRAMOVAY, Miriam; GARCIA, Mary. Ensino médio: múltiplas vozes. Brasília: UNESCO, 2003.

ALMEIDA, Sinara Mota Neves de. Avaliação das concepçôes de violência no espaço escolar e a mediação de conflitos. 2009. 189f. Tese (Doutorado em Educação), Programa de Pós-Graduação em Educação Brasileira, Universidade Federal do Ceará, Fortaleza, 2009.

BARREIRA, César; BATISTA, Élcio. Violência e conflito social. In: BARREIRA, César; BATISTA, Élcio. (Orgs.). Segurança e Sociedade. Campinas: Pontes, 2011. p. 19-36.

BOURDIEU, Pierre. O Poder Simbólico. Rio de Janeiro: Bertrand Brasil, 1989.

FREITAS, Geovani Jacó de; BRASIL, M. Glaucíria Mota; ALMEIDA, Rosemary de Oliveira. Morte em fronteiras: jovens "matáveis" nos celeiros da política e da cidade. Configuraçóes, v. 10, p. 1-16, 2012. Disponível em: <http://configuracoes.revues.org/1509>. Acesso em: 15 nov. 2015.

GEERTZ, Cliford. A Interpretação das Culturas. Rio de Janeiro: LTC, 2008.

NETO, Adolfo Braga. Mediação de Conflitos: Princípios e Norteadores. Revista da Faculdade de Direito UniRitter, Porto Alegre, v. 1, n. 11, p. 29-46, 2010. 
134 | Katury Ramos, Rosemary Almeida e Sinara Almeida

POCHMANN, Marcio. Juventude em busca de novos caminhos no Brasil. In: NOVAES, Regina; VANNUCHI, Paulo (Orgs.). Juventude e Sociedade: trabalho, educação, cultura e participação. São Paulo: Editora Fundação Perseu Abramo, 2014.

PRANIS, Kay. Processos circulares: teoria e prática. São Paulo: Palas Athena, 2010.

SALES, Lília Maia de Morais. Justiça e mediação de conflitos. Belo Horizonte: Del Rey, 2004.

SIMMEL, Georg. Sociologia. São Paulo: Ática, 1983.

TERRE DES HOMMES. Prevenindo a violência e promovendo a justiça juvenil restaurativa: justiça juvenil restaurativa e práticas de resolução positiva de conflitos. Fortaleza: Terre des Hommes, 2013.

VEZZULLA, Juan Carlos. A mediação de conflitos com adolescentes autores de ato infracional. 2004. 98f. Dissertação (Mestrado em Serviço Social), Programa de Pós-graduação em Serviço Social, Universidade Federal de Santa Catarina, Florianópolis, 2004.

VIANNA, Marcio dos Santos. Mediação de conflitos: Um novo paradigma na Administração da Justiça. Âmbito Jurídico, Rio Grande, v. 12, n. 71, dez. 2009. Disponível em: $<$ http: $</ /$ www.ambitojuridico.com.br/site/index.php?n_link=revista_artigos_leitura\&artigo_id=6991>. Acesso em: 26 jun. 2014.

WACQUANT, Loïc. As prisóes da miséria. Rio de Janeiro: Jorge Zahar: 2005.

WIEVIORKA, Michel. O Novo Paradigma da Violência. Tempo Social, São Paulo, v. 9, n. 1, p. 0538, 1997.

Texto recebido em 08 de julho de 2017. Aprovado em 21 de julho de 2017. 